\title{
Comparison of the effects of isoflurane and sevoflurane on surgical stress in intracranial tumor surgery
}

\author{
Vuslat Muslu Erdem ${ }^{\oplus}$, Halil Erkan Sayan² ${ }^{2}$, Şefika Gülsen Korfalı ${ }^{3} \odot$ \\ ${ }^{1}$ Department of Anesthesiology and Reanimation, Lütfiye Nuri Burat State Hospital, Istanbul, Turkey \\ ${ }^{2}$ Department of Anesthesiology and Reanimation, University of Health Sciences, Bursa Yüksek İhtisas Training and Research Hospital, \\ Bursa, Turkey \\ ${ }^{3}$ Department of Anesthesiology and Reanimation, Uludağ University School of Medicine, Bursa, Turkey
}

\begin{abstract}
Objectives: Surgeries can trigger stress responses including metabolic and hormonal changes. It is important to suppress stress response during surgery. We compared the effects of isoflurane and sevoflurane on surgical stress in intracranial tumor surgery.

Methods: Thirty ASA physical status I, II, III patients, scheduled for elective craniotomies, were enrolled in this prospective, randomized study. Anesthesia was induced with sodium thiopental fentanyl and vecuronium bromide and maintained with a 50\% oxygen-air mixture along with isoflurane or sevoflurane. Venous blood was sampled to measure cortisol, ACTH and prolactin levels 24 hours before surgery, $1 \mathrm{~min}$ before anesthesia induction, during tumor removal, 1 min after extubation, at 3, 6, 12, 24, 48 hours.

Results: There was no statistically significant difference between two groups regarding demographic characteristics of patients. In group I, ACTH levels were significantly higher $1 \mathrm{~min}$ after extubation, at 3 and 6 hours. In Group S, significant increases were observed during tumor removal, 1 min after extubation, at 3 and 6 hours. Cortisol levels were significantly higher in both group after tumor removal, 1 min after extubation, at 3, 6, 12 and 24 hours. Prolactin levels were significantly higher in Group I during tumor removal, after extubation, at 3 and 6 hours. In group S, significant increase in prolactin level was observed only during tumor removal and $1 \mathrm{~min}$ after extubation. There were no significant differences in ACTH, cortisol and prolactin values between the two groups.
\end{abstract}

Conclusions: Using isoflurane or sevoflurane for anesthesia during intracranial tumor surgery are not superior to each other regarding hemodynamic and hormonal stress response.

Keywords: surgical stress, isoflurane, sevoflurane, catecholamines, ACTH, cortisol

Grics eneral anesthetic agents, opioids, local anesthetics and various regional anesthesia techniques have been tried to suppress the excessive stress response which may be caused by surgical intervention $[1,2]$. One of the important aims of the search for new anesthetic agents is to find the ideal anesthetic agent that suppresses stress response and limits the neuroen- docrine, inflammatory and immune response [3]. It is stated that an anesthetic agent with these properties may contribute to the improvement of the postoperative period and the shortening of hospital stay [3].

The potent volatile anesthetics all induce myocardial depression with dose-dependent reductions in blood pressure and cardiac output, although the mech- 
anisms for decline in blood pressure and the degree of myocardial depression [4].

Isoflurane is suppress the excessive stress response mechanisms include metabolic suppression, inhibition of sympathetic activity, reduction of glutamate receptors which are prevent calcium flow and suppression of excitotoxicity of calcium cascade [5]. Isoflurane and sevoflurane have primary vasodilatory properties, thereby reducing systemic vascular resistance with relatively little initial effect on cardiac inotropy [4].

Most elective neurosurgical interventions are performed because of intracranial mass lesions. Although pathological reasons for these lesions are different, anesthesia applications are similar [6].

In this study, we aimed to assess the effects of isoflurane and sevoflurane on hemodynamics and hormonal responses to elective intracranial tumor surgery. The secondary objective was the investigate suppression of the adrenergic response by monitoring hemodynamic parameters: systolic and diastolic arterial pressure and heart rate.

\section{METHODS}

After the approval of the Ethics Committee of Uludag University School of Medicine (Decision number: 04.04.2003-2783); thirty American Society of Anesthesiologists (ASA) classification I-II-III, patients were enrolled, for an intracranial intracranial tumor surgery under elective conditions. Written informed consents were obtained from all patients.

The exclusion criteria were as follows: Patients who were previously had an operation for the same tumor, whom had pituitary adenomas, have allergies to anesthetic drugs, developed an air embolism during the operation, were taken into the surgery within 48 hours after the operation and pregnancy.

The patients were randomly divided into two groups. Isoflurane (Group I; $\mathrm{n}=15$ ) and sevoflurane (Group $\mathrm{S} ; \mathrm{n}=15$ ) group by sealed envelope (Fig. 1). Prior to induction arterial catheter was inserted for continuous blood pressure monitoring and blood sampling. Three-lead electrocardiogram (ECG), peripheral oxygen saturation $\left(\mathrm{SpO}_{2}\right)$, the end-tidal concentrations of the volatile anesthetics and the $\mathrm{ETCO}_{2}$ were monitored continuously.

Before the induction of anesthesia, $1 \mathrm{mg} . \mathrm{kg}^{-1}$ li- docaine was given intravenously to reduce hemodynamic response to the intubation. All patients were induced with sodium thiopental according to ideal body weight (3-5 mg. $\left.\mathrm{kg}^{-1}\right)$, fentanyl $\left(2 \mu \mathrm{g} . \mathrm{kg}^{-1}\right)$ and vecuronium bromide $\left(0.1 \mathrm{mg} . \mathrm{kg}^{-1}\right)$. In the maintenance, the volatile anaesthetic (0.8-1.2 MAC) was given in a mixture of $50 \%$ oxygen-air according to the study group. Ventilation was controlled mechanically in order to achieve an end-tidal $\mathrm{CO}_{2}$ between 30-35 $\mathrm{mmHg}$.

Each patient was treated with fentanyl $2 \mu \mathrm{g}$. $\mathrm{kg}^{-1} 5$ min prior to placement of the skull clamp. The vecuronium bromide $\left(0.02 \mathrm{mg}\right.$. $\left.\mathrm{kg}^{-1}\right)$ was administered as the neuromuscular blocking drug according to train -of four monitoring. Hemodynamic response of at least one minute in duration were defined as hypertension (mean arterial pressure $>20 \%$ from the baseline measurement), tachycardia (heart rate $>20 \%$ from the base line measurement), and bradycardia (heart rate < 45/minute). Hypertension and tachycardia were treated with bolus fentanyl $\left(1 \mu \mathrm{g} . \mathrm{kg}^{-1}\right)$ as arescue drug to prevent pain and increased hemodynamic response. Hypotension was treated fluid bolus. Hypotension unresponsive to a fluid bolus was treated by ephedrine sulfate 5-10 mg intravenous bolus injection. For bradycardia, anticholinergic drugs were administered. After the operation, patients were extubated and transferred to Neurosurgical Intensive Care Unit.Pain requiring rescue medication (Visual Analog Scale above 5) were treated with non-steroidal anti-inflammatory agent.

Hemodynamic data were monitored throughout the operation. Heart rate (HR), systolic arterial pressure (SAP), diastolic arterial pressure (DAP) and mean arterial pressure (MAP) were recorded in 12 different times: one minute before anesthesia induction (T1), one minute after intubation (T2), during skull clamping (T3), skin incision (T4), craniotomy (T5), dura incision (T6), tumor removal (T7), dural closure (T8), bone closure (T9), skin closure (T10), one minute before extubation (T11) and one minute after extubation (T12). Peripheral blood samples were collected 24 hours before surgery (P1), one min before anesthesia induction (P2), during tumor removal (P3), one minute after extubation (P4), at 3 hours (P5), at 6 hours (P6), at 12 hours (P7), at 24 hours (P8), and at 48 hours (P9) (Fig. 1).

Five cc peripheral blood samples were taken and 


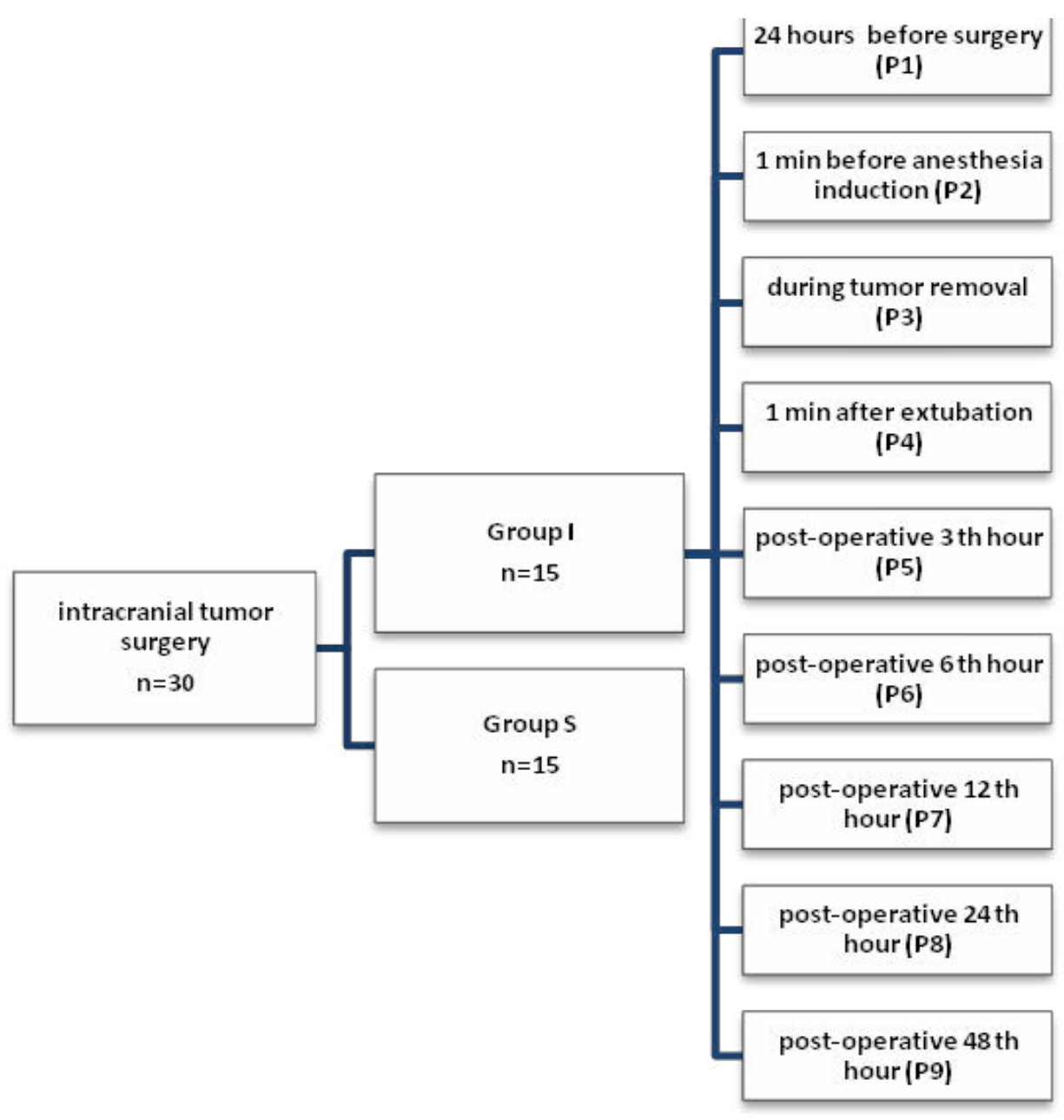

Fig. 1. Flow diagram and peripheral blood samples. $P=$ period, $\min =\operatorname{minute}, I=$ isoflurane, $S=$ sevoflurane

placed into $2.5 \mathrm{cc}$. dry tubes and $2.5 \mathrm{cc}$. citrated tubes. Samples were centrifuged at $5000 \mathrm{rpm}$ for 10 minutes and separated from their shaped components as plasma and serum. Plasma and serum samples were taken with an automatic pipette and placed in separate plastic ependymoma tubes and coded. It was frozen at $-500{ }^{\circ} \mathrm{C}$ for further processing.

After all samples were collected, serum samples were brought to room temperature to measure Prolactin, Cortisol and ACTH levels. The measurements were made at the Uludag University School of Medicine Central Laboratory. For ACTH measurements, IMMULITE $^{\circledR}$ ACTH (Siemens, Germany) measurement kit was used. Quantitative ACTH measurements were performed on plasma samples with this kit. The ADVIA ${ }^{\circledR}$ Centaur $^{\mathrm{TM}}$ (Siemens, Germany) system was used to measure the prolactin levels. In this system, prolactin levels in serum samples were detected by two-stage immuno analysis technique. For cortisol measurement, COAT-A-COUNT ${ }^{\circledR}$ (Siemens, Germany) Cortizol measurement kit was used. Using this kit, radioimmune analysis technique was used for the quantitative determination of cortisol level in serum. COAT-A-COUNT ${ }^{\circledR}$ Cortisol measurement kit is $98 \%$ sensitive and highly specific.

\section{Statistical Analysis}

A power analysis was performed prior to the study. According to the power analysis 15 patient per group should be enrolled to detect at least $20 \%$ difference in MAP measurement among the groups. The $\alpha$ error was set a 0.05 and the type II error was set at 0.20. All data was coded and evaluated on a computer and statistical analyzes were obtained from the SPSS for Windows Version 22.0 Statistics module. Continuous values were presented in the form of mean and standard deviation or median (minimum - maximum). Categorical data were presented as frequency (n, \%). The normal 
Table 1. Demographic characteristics of thepatients and duration of the operation

\begin{tabular}{lccc}
\hline & $\begin{array}{c}\text { Isofluran Group } \\
(\mathbf{n}=\mathbf{1 5})\end{array}$ & $\begin{array}{c}\text { Sevofluran Group } \\
(\mathbf{n = 1 5})\end{array}$ & $p$ value \\
\hline Gender (M/F) & $5 / 10$ & $5 / 10$ & \\
Age (year) & $53.2 \pm 17.2$ & $44.4 \pm 14.1$ & 0.57 \\
Weight (kg) & $67.9 \pm 10.7$ & $72.4 \pm 12.5$ & 0.20 \\
Height (cm) & $165.5 \pm 9.5$ & $168.2 \pm 7.6$ & 0.50 \\
Duration of the operation(min) & $352.6 \pm 92$ & $300.0 \pm 87.6$ & 0.64 \\
\hline
\end{tabular}

Data are shown as mean \pm standartd deviation or number. $\mathrm{M}=$ Male, $\mathrm{F}=$ Female

distribution of continuous data was primarily tested using the Kolmogorov-Smirnov test. Kruskal-Wallis test was used for comparisons not normal distribution. Bonferroni test was used for pairwise comparisons when their significance. Pearson chi- square test was used to compare the ratios in the groups. The t-test was used to compare group ratios and the Mann-Whitney $\mathrm{U}$ test was used to compare group percent changes. The measurement averages over time in the drug groups were compared with the Variance Analysis in Repeated Measurements. The significance of the changes over time was investigated by paired t-test and Wilcoxon rank sum tests. In all statistical analyzes, $p<0.05$ significance level was accepted.

\section{RESULTS}

There was no significant difference between two groups in terms of age, sex, weight, height. Duration of operation in isoflurane group was $352.6 \pm 92$ minutes and operation time in sevoflurane group was $300.0 \pm 87.6$ minutes. There was no significant differences in operation time between two groups $(p=$ 0.642) (Table 1).

There was no significant differences regarding MAP between the two groups. However, in within groups comparison, MAP were statistically lower one minute after intubation, during skin incision, craniotomy, dural incision, tumor removal, dural closure, bone closure and skin closure $(p-$ values are $p<0.05$, $p<0.01, p<0.01, p<0.01, p<0.01, p<0.01, p<$ $0.01, p<0.01)$ (Fig. 2).

Heart rates were significantly lower one minute after intubation, during skin incision, craniotomy, dural incision, tumor removal, dural closure, and skin closure. ( $p$ - values are $p<0.05, p<0.01, p<0.01, p$ $<0.01, p<0.01, p<0.01, p<0.01, p<0.05$ ) (Fig. 3).

ACTH levels were significantly increased one minute after extubation, at 3 and 6 hours in group I ( $p$ $<0.01)$. In Group S, significant increases were observed during tumor removal, one minute after extubation, at 3 and 6 hours. $(p<0.05, p<0.01, p<0.01$, $p<0.01$ ) (Fig. 4).

Cortisol levels were significantly higher in both groups during tumor removal, one minute after extubation, at 3, 6, 12 and 24 hours. (Group I: $p<0.01, p$ $<0.01, p<0.01, p<0.01, p<0.01, p<0.01$; Group $\mathrm{S}: p<0.01, p<0.01, p<0.01, p<0.01, p<0.01, p<$ 0.05) (Fig. 5).

Prolactin levels significantly increased in Group I during tumor removal, one minute after extubation, at 3 and 6 hours. $(p<0.01, p<0.01, p<0.05, p<0.05)$. In group $\mathrm{S}$, significant increases in prolactin level were observed only during tumor removal and one minute after extubation $(p<0.01, p<0.01)$ (Fig. 6). No significant differences were found between the two groups in $\mathrm{ACTH}$, cortisol and prolactin levels.

\section{DISCUSSION}

It has been reported that response to surgical stress, increased metabolism, catabolism, and other physiological changes predispose to severe post-operative complications such as myocardial infarction, pulmonary infection, thromboembolism [7]. Suppression of surgical stress responses can lead to shorter healing duration, shorter hospitalization duration after the surgery and reduce the hospital costs especially for patients with malnutrition, suppressed immune system, elderly patients and ASA III-IV patients. For these rea- 


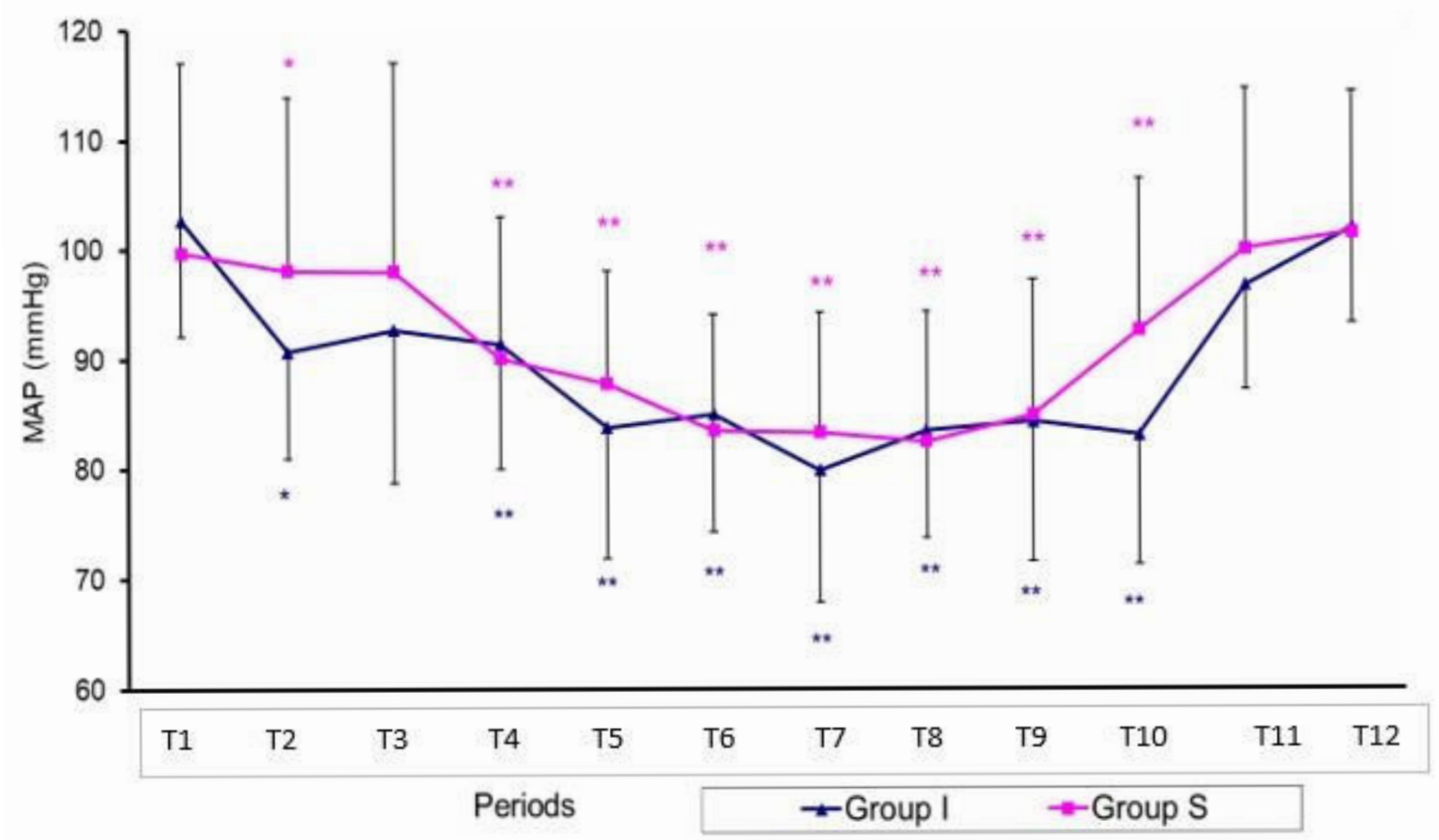

Fig. 2. Mean arterial pressure (MAP) $($ mean \pm SD). Within group $* p<0.05, * * p<0.01$. SD $=$ Standard deviation. Periods: $\mathrm{T} 1=$ one minute before induction, $\mathrm{T} 2=$ one minute after intubation, $\mathrm{T} 3=$ during skull clamping, $\mathrm{T} 4=$ skin insicion, $\mathrm{T} 5=$ craniotomy, $\mathrm{T} 6=$ dural incision, $\mathrm{T} 7=$ tumor removal, $\mathrm{T} 8=$ dural closure, $\mathrm{T} 9=$ bone closure, $\mathrm{T} 10=\mathrm{skin}$ closure, $\mathrm{T} 11=\mathrm{one}$ minute before extubation, $\mathrm{T} 12=$ one minute after extubation.

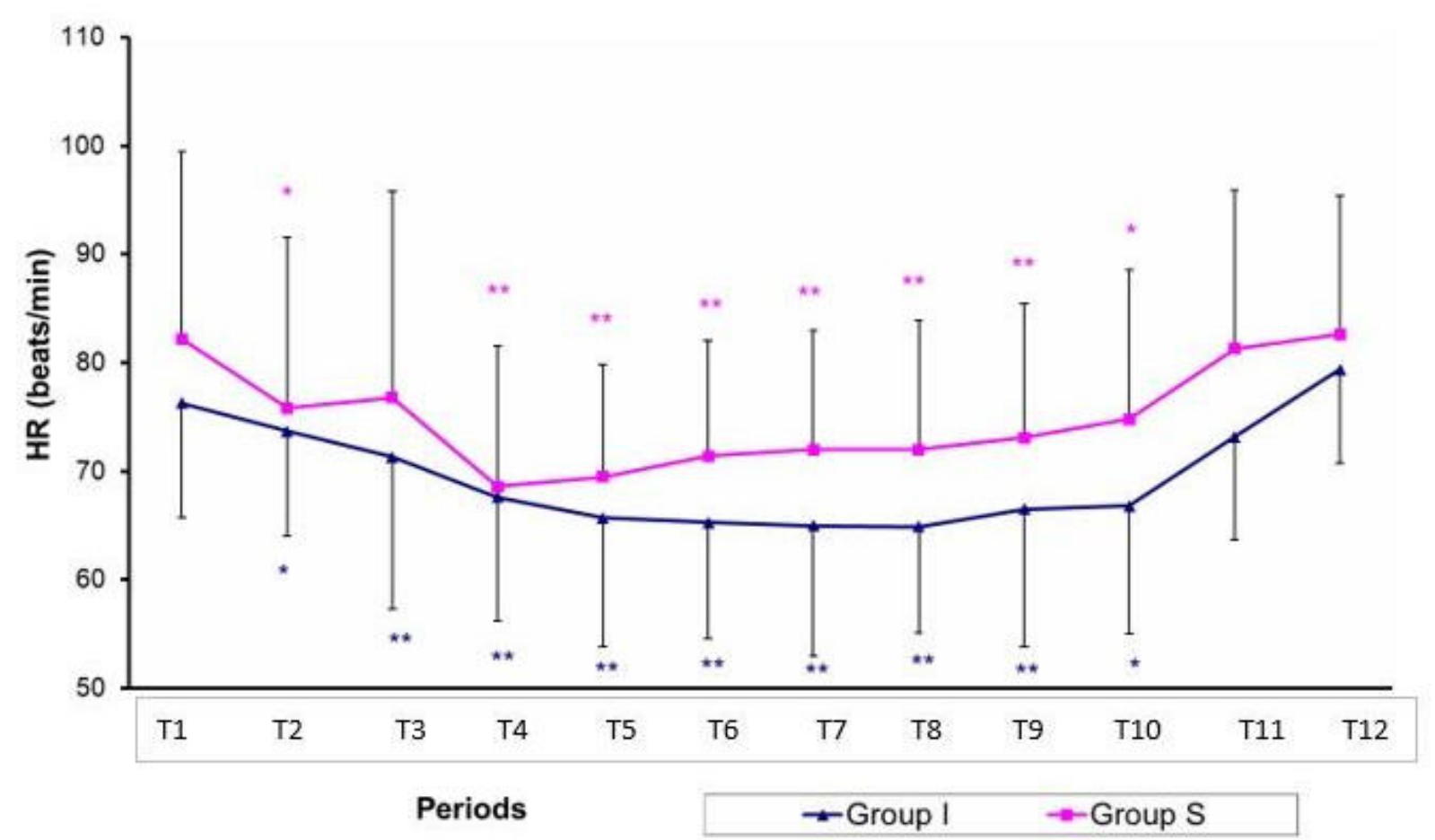

Fig. 3. Heart rate (HR) $($ mean \pm SD). Within group $* p<0.05, * * p<0.01 . \mathrm{SD}=$ Standard deviation. Periods: T1 $=$ one minute before induction, $\mathrm{T} 2=$ one minute after intubation, $\mathrm{T} 3=$ during skull clamping, $\mathrm{T} 4=$ skin insicion, $\mathrm{T} 5=\mathrm{craniotomy}$, $\mathrm{T} 6=$ dural incision, $\mathrm{T} 7=$ tumor removal, $\mathrm{T} 8=$ dural closure, $\mathrm{T} 9=$ bone closure, $\mathrm{T} 10=$ skin closure, $\mathrm{T} 11=$ one minute before extubation, $\mathrm{T} 12$ = one minute after extubation. 


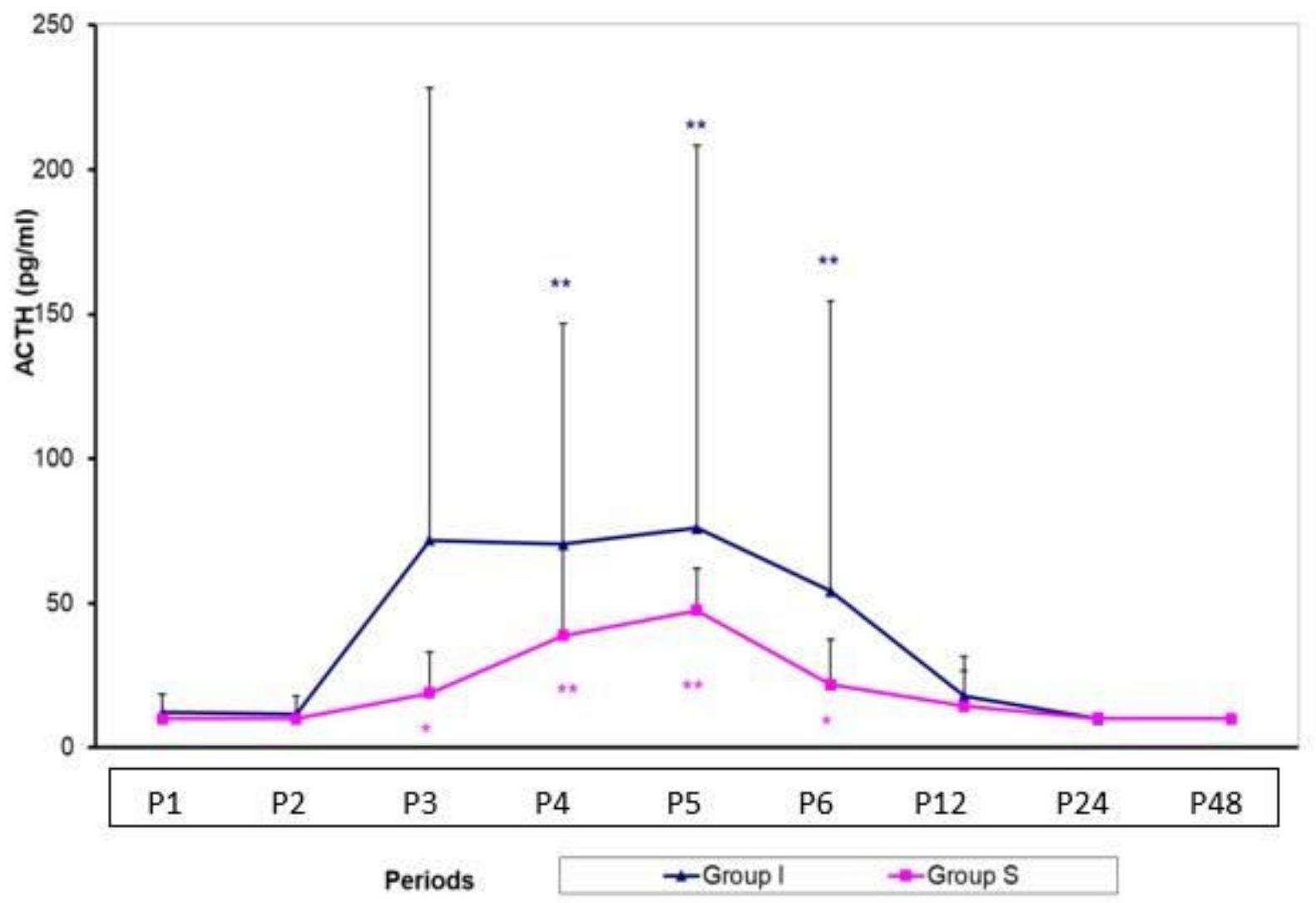

Fig. 4. ACTH levels (mean \pm SD). Within group $* p<0.05, * * p<0.01$. SD $=$ Standard deviation. Periods: P1 $=24$ hours before surgery, $\mathrm{P2}=$ one minute before induction, $\mathrm{P3}=$ during tumor removal, $\mathrm{P} 4=$ one minute after extubation, $\mathrm{P5}=$ at 3 hours, P6 = at 6 hour, P12 = at 12 hours, P24 = at 24 hours. P48 = at 48 hours.

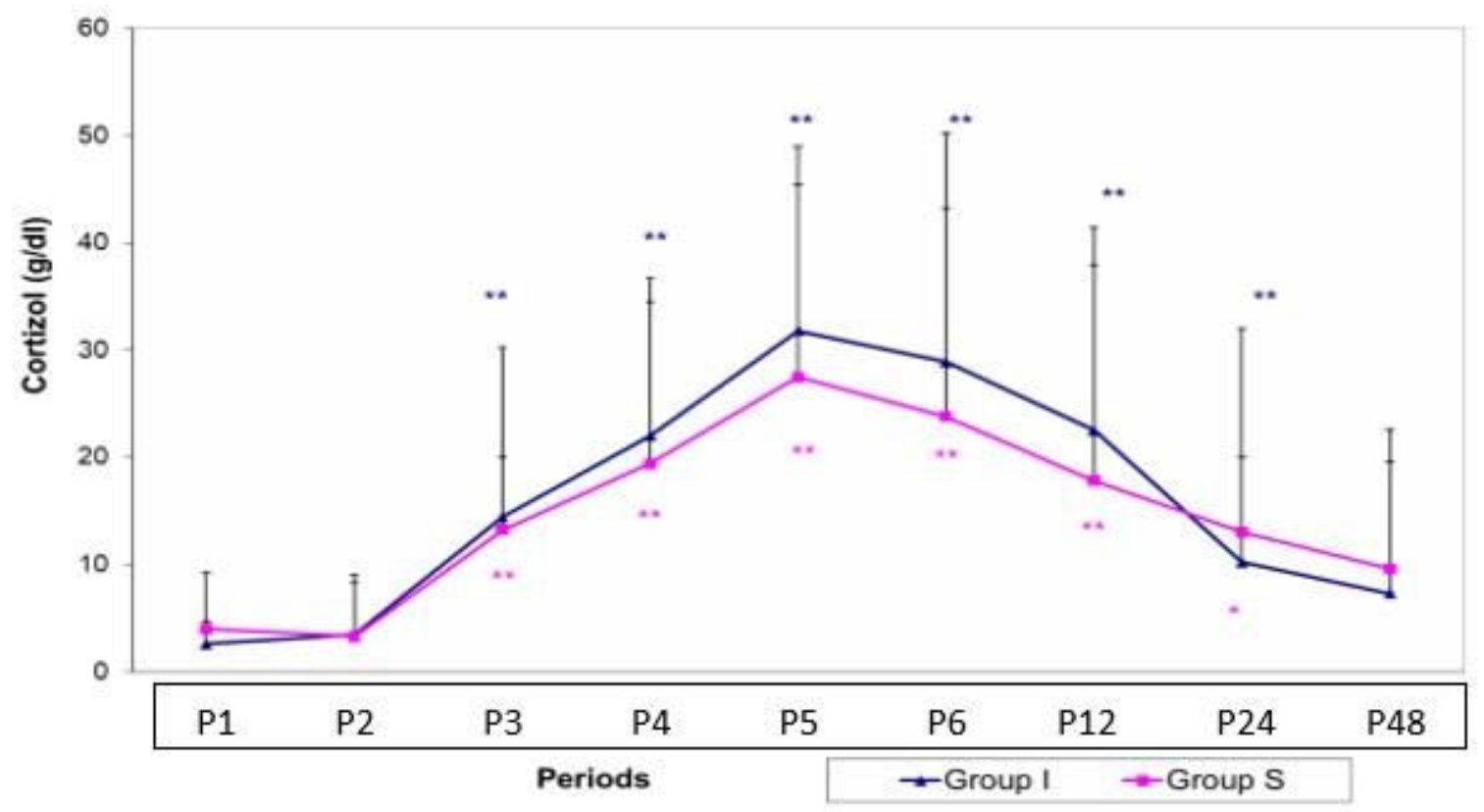

Fig. 5. Cortizol levels (mean \pm SD). Within group $* p<0.05, * * p<0.01 . S D=$ Standard deviation. Periods: P1 $=24$ hours before surgery, $\mathrm{P2}=$ one minute before induction, $\mathrm{P3}=$ during tumor removal, $\mathrm{P} 4=$ one minute after extubation, $\mathrm{P5}=$ at 3 hours, $\mathrm{P6}=$ at 6 hour, $\mathrm{P} 12=$ at 12 hours, $\mathrm{P} 24=$ at 24 hours. $\mathrm{P} 48=$ at 48 hours. 


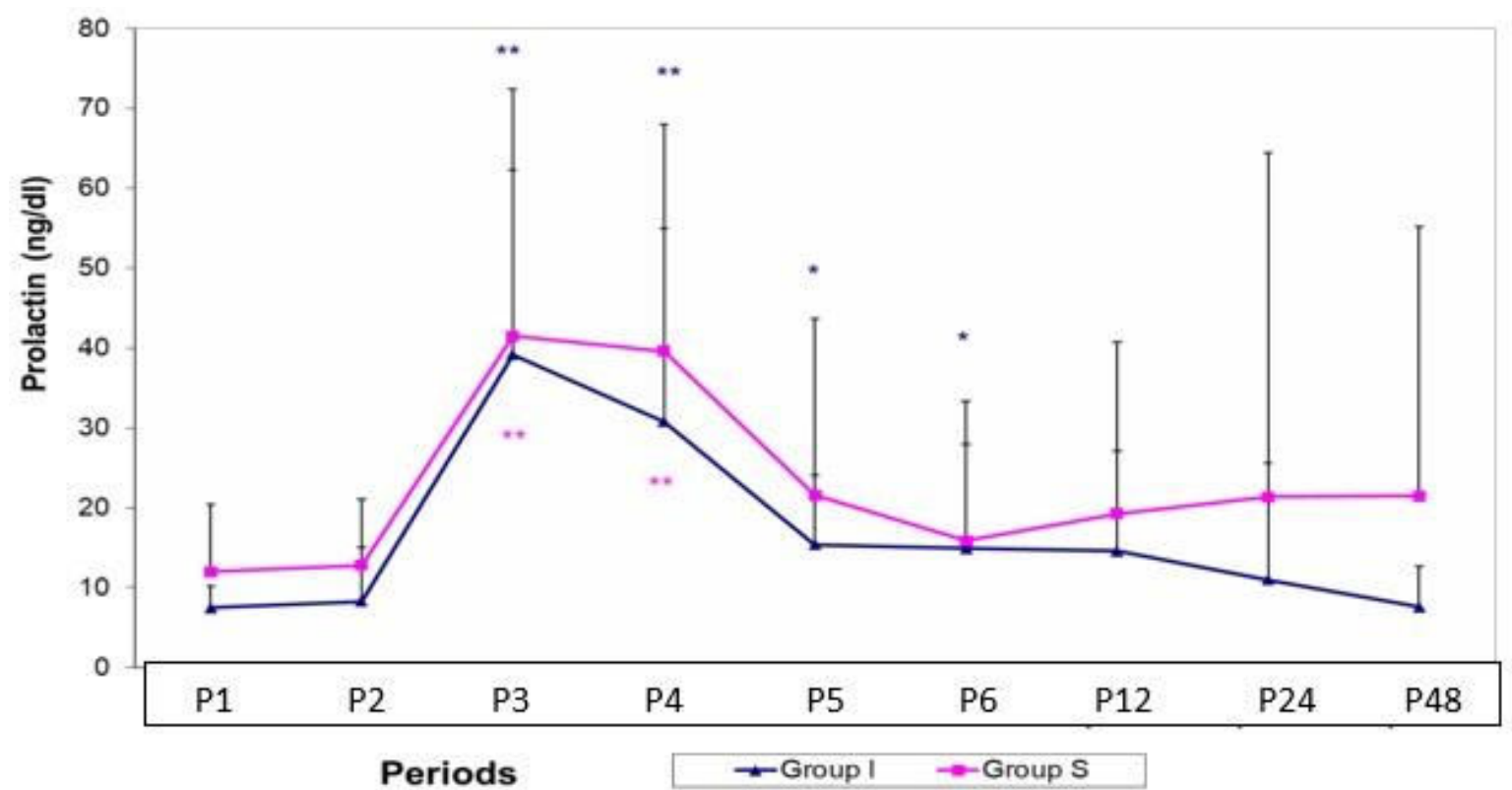

Fig. 6. Prolactin levels $($ mean \pm SD). Within group $* p<0.05, * * p<0.01 . \mathrm{SD}=$ Standard deviation. Periods: P1 $=24$ hours before surgery, $\mathrm{P2}=$ one minute before induction, $\mathrm{P3}=$ during tumor removal, $\mathrm{P} 4=$ one minute after extubation, $\mathrm{P5}=$ at 3 hours, P6 = at 6 hour, P12 = at 12 hours, P24 = at 24 hours. P48 = at 48 hours.

sons, suppression of stress responses has critical importance [8].

It has been shown that the hypothalamic-pituitary-adrenal axis can be depressed with high dose opioids during the surgical procedure and the stress response can be partially controlled [9-11]. There are also other studies that show that regional anesthesia techniques and local anesthetics are successful in suppressing stress response [9, 12-17].

In the post-surgical period, the stress responses can be controlled with a good pain therapy. It has also been suggested that $\beta$-blocker, $\alpha-2$ agonist, $\mathrm{Ca}+2$ channel blockers may be used to reduce stress hormone secretion and the effects of these hormones on target organs in some cases $[1,18,19]$.

A few experimental studies have investigated the effects of volatile anesthetic agents such as isoflurane and sevoflurane on the hormonal and immunological responses [20,21]. The effects of usage of isoflurane and sevoflurane during anesthesia on the hormonal stress responses which develop as a result of surgical traumas are still unclear [12].

Sympathetic adrenergic response to surgical stimuli clinically manifests itself as hypertension, increased heart rate and body temperature [1]. Opioids suppress sympathetic adrenergic response [1, 10]. However, intravenous or volatile anesthetic agents have not been able to suppress this response [22]. Segawa et al. [22] investigated the effects of sevoflurane and isoflurane at different concentrations on adrenaline and noradrenalin levels in blood during liver transplantations. The reduction of blood pressure increase due to surgical stimulation with volatile anesthetic agents was reported to be the result of suppression of the effects of catecholamines on vascular smooth muscles and myocardium [22].

Ura et al. [23] studied serum noradrenalin levels in patients who received sevoflurane anesthesia at different concentrations to determine the concentration of sevoflurane that could prevent the adrenergic response to surgical incision and the increase in mean arterial pressure.

Stress hormone levels in blood have been reported to suddenly increase up to 10 to 100 times of normal levels due to endotracheal intubation and surgical stimulation and gradually decrease to baseline levels within hours or days [24, 25]. Murakawa et al. [26] investigated the effects of sevoflurane anesthesiaon serum cortisol levels in gastrointestinal and gynecological surgeries. They found that there was no change in serum cortisol levels after anesthesia induction with sevoflurane, but cortisol levels increased 2-3 times of the pre- anesthetic levels during and after surgery [26]. We also found a rapid increase in $\mathrm{ACTH}$, cortisol, and 
prolactin levels during surgery, reaching 6-7 times of pre-anesthetic levels in both groups in our study.

Roth-Isigkeit et al. [27] reported that plasma ACTH and cortisol levels increased during the study in patients who underwent coronary artery bypass graft surgery. They found that while ACTH levels decreased to baseline levels after 24 to 48 hours postoperatively, cortisol levels remained significantly higher at 72 hours in postoperative period compared to preoperative period. In our study, we also found that cortisol levels were significantly higher at the 24th postoperative hour compared to baseline levels in both groups. However, ACTH levels were returned to their baseline levels at the $12^{\text {th }}$ postoperative hour in both groups.

Hase et al. [25] studied the effects of isoflurane and sevoflurane, with combination of epidural anesthesia during the gastric surgery in elderly patients. They looked at the ACHT, cortisol, adrenaline and noradrenaline levels during and after surgery. They found that there was no statistically significant difference between the two groups. Marana et al. [28] compared TIVA with propofol versus sevoflurane anesthesia. TIVA inhibited ACTH-cortisol axis and reduced NE, $\mathrm{E}$ and $\mathrm{GH}$ levels but it enhanced prolactin as compared with sevoflurane.

Marane et al. [29] compared the effects of desflurane versus sevoflurane anesthesia on intra and postoperative release of the stress hormones and inflammatory cytokines in laparoscopic surgery. Although a decrease in cortisol concentration level was observed in both groups, only in the DES group there was a significant difference in intraoperative cortisol levels as compared to the baseline levels. The consequent increase of ACTH level was significantly higher in the SEVO group at 30 minutes after the beginning of surgery and at 4 hours after the end of surgery. They concluded that desflurane and sevoflurane produced a different stress response in the setting of laparoscopic surgery [29]. In our study, there was no statistical differencebetween isoflurane and sevoflurane group in terms of hormone levels. The surgical stress levels are known to be relatively lower in laparoscopic surgeries compared to intracranial tumor surgeries.

Krog's study [30] showed that Cortisol and ACTH levels are statistically lower in laparoscopic aortabifemoral bypass group than open aorta-bifemoral bypass group. The patients operated with a laparoscopic aorta-bifemoral bypass achieved earlier hormonal homeostasis after surgery compared to open group [30]. Minimally invasive surgery seems to reduce hormonal stress response to surgery.

There are few comparative studies of stress hormone changes during long surgeries under general anesthesia. Nishiyama et al. [31] showed that isoflurane-nitrous oxide and sevoflurane-nitrous oxide had the same effects on stress hormone changes except for epinephrine, norepinephrine, and ADH levelsduring inhalation anesthesia with the duration of more than 10 hours. We also found that there were no statistically significant differences in $\mathrm{ACTH}$, cortisol and prolactin levels in blood; before, during and after the surgery between the two groups. We think that our results might have been affected because intracranial tumor surgery are longer and highly stressful operations.

Miura et al. [24] administered isoflurane, ketamine and fentanyl $-\mathrm{N}_{2} \mathrm{O}$ anesthesia to the rats with incomplete cerebral ischemia and looked at noradrenalin levels in the carotid and hippocampus. They found that the noradrenalin levels in blood and brain were changed independently of each other and the anesthesia method [24]. Partial ischemia may occur during intracranial mass surgery. Depending on the localization of the tumor, this can lead to changes in the secretion of the hypophyseal hormones. In our study, we found a very high ACTH level in one patient during tumor removal in sevoflurane group (Fig. 4). We attributed this to the tumor localization and therefore the surgical field's closeness to the pituitary gland.

Mustolo et al. [32] compared the effects of sevoflurane-fentanyl and isoflurane-fentanyl on the surgical stress index. They found that surgical stress index was higher in sevoflurane-fentanyl group.

\section{Limitations}

The limitation of our study was relatively small number of patients the power analyze. In our study we used special laboratory kit. Because of our limited financial resource we could not Increase the number of patients. Thus more patients needed in future studies to confirm our results.

\section{CONCLUSION}

As a result, isoflurane or sevoflurane anesthesia 
has similar effects in terms of hemodynamic and hormonal stress response during intracranial tumor surgery.

\section{Authors' Contribution}

Study Conception: ŞGK; Study Design: ŞGK; Supervision: ŞGK; Funding: ŞGK; Materials: HES; Data Collection and/or Processing: VME; Statistical Analysis and/or Data Interpretation: HES; Literature Review: HES; Manuscript Preparation: VME and Critical Review: HES.

\section{Conflict of interest}

The authors disclosed no conflict of interest during the preparation or publication of this manuscript.

\section{Financing}

The authors disclosed that they did not receive any grant during conduction or writing of this study.

\section{REFERENCES}

1. Breslow MJ. Clinical Implications of the stress response to surgery. In: Rogers, MC., Tinker, JH., Covino, BG., Longnecker D, ed. Principles and Practice of Anesthesiology. 2nd. Mosby; 1998:103-120.

2. Chi OZ, Choi YK, Lee DI, Kim YS, Lee I. Intraoperative mild hypothermia does not increase the plasma concentration of stress hormones during neurosurgery. Can J Anaesth 2001;48:815-8.

3. Galley HF, DiMatteo MA, Webster NR. Immunomodulation by anaesthetic, sedative and analgesic agents: does it matter? Intensive Care Med 2000;26:267-74.

4. Torri G. Inhalation anesthetics: a review. Minerva Anestesiol 2010;76:215-28.

5. Milde LN. Cerebral protection. In: Cucchiara RF, Black S, Mchenfelder JD (eds.). Clinical Neuroanesthesia. New York: Churchill Livingstone, 1998: pp.177-228.

6. Yörükoğlu D. Tümör cerrahisinde anestezi. In: Kecik Y, ed. Nöroanestezi. 1. Bask1. Ankara: Atlas Yayınc1lı; 2000:171-198.

7. Kehlet H. The surgical stress response: should it be prevented? Can J Surg 1991;34:565-7.

8. Chrousos GP. The role of stress and the hypothalamic-pituitary-adrenal axis in the pathogenesis of the metabolic syndrome: neuro-endocrine and target tissue-related causes. Int J Obes 2000;24:S50-5.

9. Aono H, Takeda A, Tarver SD, Goto H. Stress responses in three different anesthetic techniques for carbon dioxide laparoscopic cholecystectomy. J Clin Anesth 1998;10:546-50.

10. Desborough JP. The stress response to trauma and surgery. Br J Anaesth 2000;85:109-17.

11. Besnier E, Clavier T, Compere V. The hypothalamic-pituitary- adrenal axis and anesthetics: a review. Anesth Analg. 2017;124:1181-9.

12. Marana E, Annetta MG, Meo F, Parpaglioni R, Galeone M, Maussier ML, et al. Sevoflurane improves the neuroendocrine stress response during laparoscopic pelvic surgery. Can J Anesth 2003;50:348-54.

13. Naito Y, Tamai S, Shingu K, Shindo K, Matsui T, Segawa H, et al. Responses of plasma adrenocorticotropic hormone, cortisol, and cytokines during and after upper abdominal surgery. Anesthesiology 1992;77:426-31.

14. Liu S, Carpenter RL, Neal JM. Epidural anesthesia and analgesia: their role in postoperative outcome. Anesthesiology 1995;82:1474-506.

15. Weissman $\mathrm{C}$. The metabolic response to stress: an overview and update. Anesthesiology 1990;73:308-27.

16. Geze S, Yilmaz AA, Tuzuner F. The effect of scalp block and local infiltration on the haemodynamic and stress response to skull-pin placement for craniotomy. Eur J Anaesthesiol 2009;26:298-303.

17. Kendrišić M, Šurbatović M, Djordjević D, Trifunović B, Jevdjić J. Analgesic efficacy and safety of four different anesthesia/postoperative analgesia protocols in patients following total hip arthroplasty. Vojnosanit Pregl 2017;74:814-20.

18. Scherpereel P. Endocrine, Immune and Metabolic stress responses to surgery. In: XXXVIII.Türk Anesteziyoloji ve Reanimasyon Kongresi-2004 Özet Kitab1. 2004:234-235.

19. Wang XW, Cao JB, Lv BS, Mi W, Wang Z, Zhang C, et al. Effect of perioperative dexmedetomidine on the endocrine modulators of stress response: a meta-analysis. Clin Exp Pharmacol Physiol 2015;42:828-36.

20. Kain ZN, Zimolo Z, Heninger G. Leptin and the perioperative neuroendocrinological stress response. J Clin Endocrinol Metab 1999;84:2438-42.

21. Goto Y, Ho SL, McAdoo J, Fanning NF, Wang J, Redmond $\mathrm{HP}$, et al. General versus regional anaesthesia for cataract surgery: effects on neutrophil apoptosis and the postoperative pro-inflammatory state. Eur J Anaesthesiol 2000;17:474-80.

22. Segawa H, Mori K, Murakawa M, Kasai K, Shirakami G, Adachi T, et al. Isoflurane and sevoflurane augment norepinephrine responses to surgical noxious stimulation in humans. Anesthesiology 1998;89:1407-13.

23. Ura T, Higuchi H, Taoda M, Sato T. Minimum alveolar concentration of sevoflurane that blocks the adrenergic response to surgical incision in women: MAC(BAR). Eur J Anaesthesiol 1999;16:176-81.

24. Miura Y, Mackensen GB, Nellgård B, Pearlstein RD, Bart RD, Dexter F, et al. Effects of isoflurane, ketamine, and fentanyl/N2O on concentrations of brain and plasma catecholamines during near-complete cerebral ischemia in the rat. Anesth Analg 1999;88:787-92.

25. Hase K, Meguro K. Perioperative stress response in elderly patients for elective gastrectomy -The comparison between isoflurane anesthesia and sevoflurane anesthesia both combined with epidural anesthesia. Japanese J Anesthesiol 2000;49:128-9. 26. Murakawa T, Tsubo T, Ogasawara H, Takahashi S, Kudo T, Matsuki A. Plasma cortisol levels during abdominal surgery under sevoflurane anesthesia: comparison between gastrointesti- 
nal and gynecological surgery. Japanese J Anesthesiol 1990;39:723-7.

27. Roth-Isigkeit AK, Schmucker P. Postoperative dissociation of blood levels of cortisol and adrenocorticotropin after coronary artery bypass grafting surgery. Steroids 1997;62:695-9.

28. Marana E, Colicci S, Meo F, Marana R, Proietti R. Neuroendocrine stress response in gynecological laparoscopy: TIVA with propofol versus sevoflurane anesthesia. J Clin Anesth 2010;22;250-5.

29. Marana E, Russo A, Colicci S, Polidori L, Bevilacqua F, Viviani $\mathrm{D}$, et al. Desflurane versus sevoflurane: a comparison on stress response. Minerva Anestesiol 2013;79:7-14.
30. Krog AH, Thorsby PM, Sahba M, Pettersen EM, Sandven I, Jørgensen J, et al. Perioperative humoral stress response to laparoscopic versus open aortobifemoral bypass surgery. Scand $\mathbf{J}$ Clin Lab Invest 2017;77:83-92.

31. Nishiyama T, Yamashita K, Yokoyama T. Stress hormone changes in general anesthesia of long duration: Isoflurane-nitrous oxide vs sevoflurane-nitrous oxide anesthesia. J Clin Anesth 2005; 17:586-91.

32. Mustola S, Parkkari T, Uutela K, Huiku M, Kymäläinen M, Toivonen J. Performance of surgical stress index during sevoflurane-fentanyl and isoflurane-fentanyl anesthesia. Anesthesiol Res Pract 2010;2010:810721. 